\title{
LXII. On the perspective representation of a circle
}

\author{
John William Lubbock Esq. F.R.S. \& L.S.
}

To cite this article: John William Lubbock Esq. F.R.S. \& L.S. (1829) LXII. On the perspective representation of a circle, Philosophical Magazine Series 2, 5:30, 420-424, DOI:

10.1080/14786442908675037

To link to this article: http://dx.doi.org/10.1080/14786442908675037

曲 Published online: 10 Jul 2009.

Submit your article to this journal ๘

山 Article views: 2

Q View related articles ¿ 
Let $a=$ volume of gas at a standard temperature as $32^{\circ}$; $\mathrm{V}=$ the volume af some other temperature: $\frac{a}{n}=$ increment by elevating the standard $1^{\circ} ; m=$ number of degrees above or below the standard. Then $a \pm \frac{m a}{n}=\mathrm{V}$. or $a=\mathrm{V} \times$ $\frac{n}{n \pm m}$. Yours, \&c.

LXII. On the Perspective Representation of a Circle. By JoHn WilliaM Lubbock, Esq. F.R.S.\& L.S.*

IET $\phi(x, z, y), \Phi^{\prime}(x, y, z)$ be the equations to any curve line; 1 let the eye of the spectator be situated at the origin of the co-ordinate axes, and let $x^{\prime}, y^{\prime}, z^{\prime}$ be the co-ordinates of any point in the conical surface whose vertex coincides with the origin, and whose base is the curve in question. The equation to this cone is found by eliminating $x, y, z$ from the equations $\phi(x y z), \Phi^{\prime}(x, y, z)$, and $x^{\prime}=\frac{x, y^{\prime}}{y}, x^{\prime}=\frac{x z^{\prime}}{z}$.

Let $\phi$ and $\phi^{\prime}$ be the equations to a straight line

$$
\begin{aligned}
& a y=b x+\alpha \\
& a z=c x+\beta
\end{aligned}
$$

The equation to the plane passing through the origin and this straight line will have for its equation

$$
\beta\left(a y^{\prime}-b x^{\prime}\right)=\alpha\left(a z^{\prime}-c x^{\prime}\right)
$$

The equation to any straight line parallel to line ( 1 ) will be

$$
\begin{aligned}
& a y=b x+\alpha^{\prime} \\
& a z=c x+\beta^{\prime}
\end{aligned}
$$

$a, b, c$ which depend on the direction of the line being the same, and the equation of the plane passing through this line will be

$$
\beta^{\prime}\left(a y^{\prime}-b x^{\prime}\right)=\alpha^{\prime}\left(a z^{\prime}-c x^{\prime}\right)
$$

The equations of the line which is the intersection of these planes are

$$
\begin{aligned}
& a y^{\prime}-b x^{\prime}=0 \\
& a z^{\prime}-c x^{\prime}=0
\end{aligned}
$$

which are the equations of a straight line parallel to lines (1) and (2) and passing through the origin.

The representation of any line is the intersection of the surface of the picture, and the plane $\beta\left(a y^{\prime}-b x^{\prime}\right)=\alpha\left(a z^{\prime}-c x^{\prime}\right)$. But it is evident, in consequence of the preceding theorem, that the representations of all lines which are parallel, will meet in the picture in the point where the line $\left\{\begin{array}{l}a y=b x \\ a z=c x\end{array}\right\}$ cuts the surface, whatever this surface may be. If the picture is a plane of which the equation is $x=A$, the equation to the re-

* Communicated by the Author. 
presentation of the line in the drawing referred to co-ordinate axes, $\mathrm{O} y$ coinciding with the intersection of the picture and the plane $x y$

$\mathrm{O} z$ coinciding with the intersection of the picture and the plane $x z$

is $\beta(a y-b \mathrm{~A})=\alpha(\alpha z-c \mathrm{~A})$; and the coordinates of the vanishing point of this line are $\frac{b \mathrm{~A}}{a}$ and $\frac{c \mathrm{~A}}{a}$; it is easy to show that the vanishing points of all lines which are situated in the same plane are in the same straight line, which line is called the vanishing line of the plane.

It is evident from the preceding theorems: that if $\mathrm{V}$ and $V^{\prime}$ (fig. 1.) are the vanishing points of any two lines, and if OCK be drawn perpendicular to $V^{V^{\prime}}$ cutting it in $\mathrm{C}$, and if $\mathrm{CK}$ be taken so that $\mathrm{CK}^{2}=\mathrm{OC}^{2}+$ $\mathrm{A}^{2}$, the angle $\mathrm{VK} \mathrm{V}^{\prime}$ is equal to the angle contained by these lines. This theorem is the foundation of the whole practice of perspective.

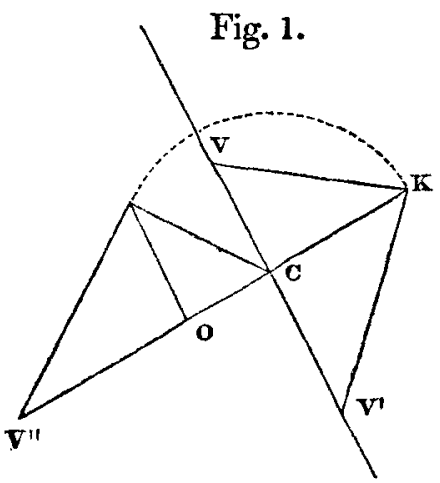

Suppose it were required to draw a circle; having drawn any diameter $A B$ and $V^{\prime} V^{\prime}$ (fig. 2.) the vanishing line of the plane in which the circle is situated by making the angle VKV' constantly equal to a right angle, and joining $\mathrm{AV}, \mathrm{BV}^{\prime}$, as many points as required may be found by the intersection $\mathrm{P}$ of $\mathrm{AV}$ and $\mathrm{BV}^{\prime}$; and this is also perhaps the simplest method of describing the curves of the second order. If the chord $\mathrm{AB}$ is given of a segment including any given angle, the same construction obtains, making $\mathrm{VKV}^{\prime}=$ to this given angle. If the circle which is to be represented be wholly without a plane passing through the eye of the spectator and parallel to the picture, the representation will be an ellipse, if it only meet

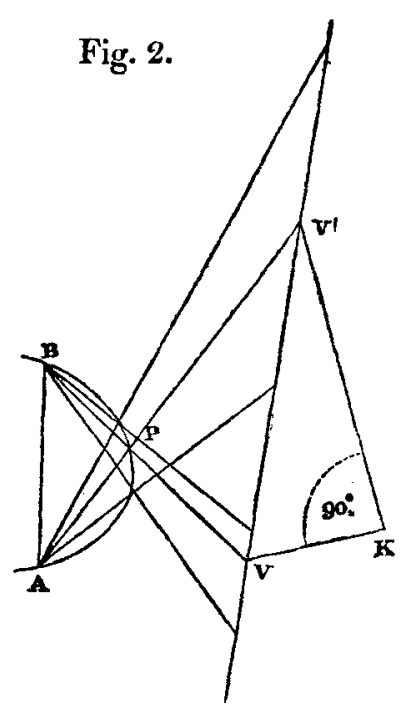
this plane it will be a parabola; if it cut the plane it will be 
a hyperbola. Thus to a spectator in an amphitheatre the inner benches are in the picture ellipses, the bench on which he is seated is a parabola, or nearly so, and the outer benches are hyperbolas.

The following construction obtains generally for curves of the second order:

Let any straight line AGB (fig. 3.) be bisected in G, at $G$ draw $G C$ perpendicular to $A B$, cutting $V^{\prime}$ in $C$, in $V V$

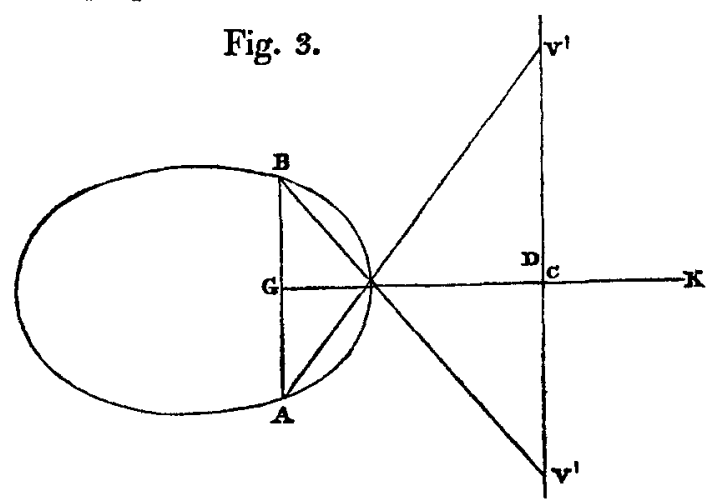

take any point $\mathrm{D}$, and make $\mathrm{DV}=\mathrm{DV}^{\prime}=\mathrm{DK}$. Join $\mathrm{AV}$, $B V^{\prime}$ the locus of the intersection of the lines $A V, B V^{\prime}$ is a curve of the second order.

If $\mathrm{VV}^{\prime}$ is parallel to $\mathrm{AB}$, and

$\mathrm{KC}>\mathrm{GA}$, the curve is an ellipse,

$\mathrm{KC}=\mathrm{GA}$, the curve is an parabola,

$\mathrm{KC}<\mathrm{GA}$, the curve is an hyperbola.

It is easy to show that if $\mathrm{VV}^{\prime}$ is the vanishing line of any plane, the vanishing point $V^{\prime \prime}$ of a line perpendicular to this plane is found by taking in OC, fig. 2. $V^{\prime \prime} \mathrm{O}=-\frac{A^{2}}{\mathrm{OC}}$, $\mathrm{A}$ being, as before, the distance of the picture.

Spherical triangles may be solved graphically by perspective by means of the preceding theorems; but this application is without practical utility, and is too simple to require development.

In crystallography, it might be convenient to mark the angles contained by planes at the vanishing point of the lines which result from their intersection, or any point in them lines produced, as in (fig. 4.) which is Stilbite, logy, page 37.)

Fig. 4.

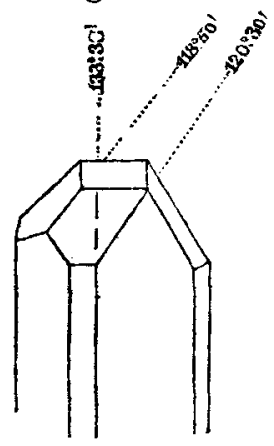

(Phillips's MineraThe 
The construction of a sun-dial is a very simple problem in perspective. In fact, if $\mathrm{OE}$ and $\mathrm{KCOG}$ (fig. 5.) are perpendicular to each other, if $\mathrm{OE}=$ the height of the style; OEG the angle which the polar axis makes with the style, which, when the dial is horizontal, is the colatitude of the place; $\mathrm{CK}=\mathrm{EC}$, the $n$th hour-line or $\mathrm{GV}_{n}$ is found by making the angle $\mathrm{CKV}_{n}=n \times 15^{\circ}$, and joining $\mathrm{GV}_{n}$. The curve which the extremity of the sun's shadow describes may be thus found:

Draw AGB (fig. 5.) perpendicular to OG. Make GD in $\mathrm{GC}=\mathrm{GE}$, and let $\mathrm{ADG}=\mathrm{BDG}=$ sun's codeclination.
Let
$\mathrm{CKV}_{5}=75^{\circ}$
$\mathrm{CKV}_{4}=60^{\circ}$
$\mathrm{CKV}_{3}=45^{\circ}$
$\mathrm{CKV}_{5}^{\prime}=7^{\circ} 30^{\prime}$
$\mathrm{CKV}_{4}^{\prime}=22^{\circ} 30^{\prime}$
$\mathrm{CKV}_{n}=n \times 15^{\circ}$
$\mathrm{CKV}_{3}^{\prime}=37^{\circ} 30^{\prime}$ $\mathrm{CKV}_{n}^{\prime}=(n-5) 15^{\circ}+7^{\circ} 30^{\prime}$.

Join $\mathrm{BV}^{\prime}$, cutting $\mathrm{GV}_{\mathrm{r}}$ in $\mathrm{P}_{1}$

$P_{n-1}, P_{n}$ cutting $G V_{n}$ in $P_{n}$,

$\mathrm{P}_{1}, \mathrm{P}_{2}, 8 \mathrm{sc} \mathrm{P}_{n}$ are points in the curve.

The problem is the same as to represent on the dial a circle situate in a plane of which VCV' is the vanishing line; EO the height of the style, being the distance of the picture, and the circle such that a perpendicular from the eye of the spectator meets the circle to be represented in its centre. This circle is in fact the circle described in the heavens by a sun whose right ascension and declination are those of the real sun $+180^{\circ}$.

The extent which a picture ought to take in, must of course be regulated by the field of view. Objects are not seen distinctly by the human eye, which subtend an angle greater

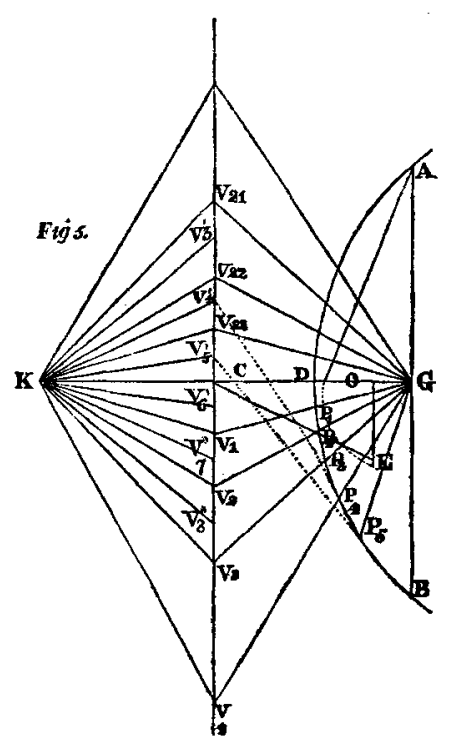
than $45^{\circ}$ with the visual axis; therefore the limit of the picture should be such that it does not contain the vanishing point of any line which makes an angle greater than $45^{\circ}$ with the axis of vision. If objects are delineated which are beyond this boundary, the perspective becomes distorted, and does not convey to the mind an accurate idea of the object which is to be represented. In representing 
the sphere of the heavens, for instance, if one hemisphere be projected on the same plane, the form of the configurations of the stars is entirely lost, and the map ceases to bear any resemblance to the appearance presented to the eye. This would not be the case if the sphere were projected upon six planes forming the sides of a cube, the eye being supposed at the centre. The distortion at the corners would be too trifling to interfere sensibly with the effect to be produced. The heavenly sphere would thus be contained in six maps, which would have the advantage of enabling any one to find any star or constellation with the greatest readiness. If the pole be taken for the centre of the upper surface of the cube, and the maps be divided by meridians and parallels of declination, the sides of the cube are symmetrical, the parallels of declination are portions of hyperbolas, and the meridians are straight lines; the upper and lower surfaces are also symmetrical, the parallels of declination are circles, and the meridians are straight lines.

LXIII. A Sketch of the Topography and Geology of Lake Ontario. By J. J. BrGsby, M.D. F.L. and G.S., For. Mem. Amer. Phil. Soc. \&c.

[Concluded from p. 347.]

7 TE next place at which I have met with conglomerate is 1 seven miles above this strait, close to a well-marked bluff promontory. Here the cement is in great quantity; and is clay, coloured by chlorite: the quartz nodules are often red, and are both rounded and angular. It is at the water's edge. Some hundred yards below the deposit of schorl on Mr. Mackenzie's farm before spoken of, elevated strata of milky quartzrock make their appearance on the beach, accompanied by the granular gneiss, containing schorl and chlorite. Resting in close contact on the quartz is a coarse conglomerate of the same materials, in a green cement; and above it is an horizontal brown limestone, full of quartz nodules at the bottom of the ledge, but which, gradually diminishing in number and size, disappear almost wholly in the upper layers. This very coarse conglomerate of milky quartz forms a ledge fifteen feet high, about three hundred yards south-west of the same deposit of schorl, close to a creek on Mr. Mackenzie's farm, and is again filled with fragments of the last-named mineral. It is in this case surrounded by debris and soil, and therefore is, as far as we can observe, unconnected with any rock. These puddingstones seem to be merely local deposits, thick and extensive as we have seen them to be; for on the shores of the 